\title{
Derrota interna, sucesso exterior: a patrimonialização do xamanismo entre os Baniwa (Alto Rio Negro - Amazonas)
}

Internal defeat, external success: the revitalization of shamanism among the Baniwa (Upper Rio NegroAmazonas)

\footnotetext{
Elise Capredon*

*École des Hautes Études en Sciences Sociales - Paris, França elisecapredon@gmail.com
} 


\title{
Resumo
}

Este artigo explora as transformações do xamanismo entre os Baniwa, um povo indígena do noroeste amazônico cujos membros se converteram na sua maioria ao cristianismo evangélico em meados do século XX. A partir de uma abordagem que enfatiza a dimensão "dialógica" das atividades xamânicas, descreve as antigas expressões da pajelança baniwa, as alterações que sofreram devido à difusão do cristianismo evangélico e as tentativas contemporâneas de reabilitação de certos dos seus aspectos através de "projetos de revitalização cultural". Ao recorrer à noção de "patrimonialização", que ajuda a pensar estas políticas culturais recentes, procuro mostrar que a pajelança baniwa está sendo dissociada dos seus antigos usos e transferida para outra esfera social, a área das relações exteriores do grupo, na qual é mobilizada principalmente para adquirir prestígio e captar recursos do mundo dos brancos. Sugiro em conclusão considerar essa nova expressão da pajelança baniwa como um "xamanismo de interface".

Palavras-chave: xamanismo; Baniwa; Alto Rio Negro; patrimonialização.

\begin{abstract}
This paper explores the transformations of shamanism among the Baniwa, an indigenous people of the Northwest Amazon whose members mainly converted to evangelicalism in the mid-20th century. Based on an approach that stresses the "dialogical" dimension of shamanic activities, it describes the ancient forms of baniwa pajelança (shamanism), the alterations they suffered due to the dissemination of evangelicalism and the contemporary attempts to rehabilitate some of their aspects through "cultural revitalization projects". By using the notion of "patrimonialization", that helps to think these recent cultural policies, I show that the baniwa pajelança is being dissociated from its former uses and transferred to another social sphere, the external relations area, in which it is mobilized primarily to gain prestige and to attract resources from the world of white people. As a conclusion, I suggest to consider this new expression of baniwa pajelança as a "shamanism of interface".
\end{abstract}

Keywords: shamanism; Baniwa; Upper Rio Negro; patrimonialization. 


\section{Introdução ${ }^{1}$}

Desde os anos 2000, várias iniciativas de revalorização do xamanismo ocorreram entre os Baniwa, um grupo indígena do noroeste amazônico cujos membros se converteram na sua maioria ao cristianismo evangélico há mais de meio século. ${ }^{2}$ Esse fenômeno, que participa de dinâmicas mais amplas de revitalização cultural entre os povos ameríndios da Amazônia, suscitou na região reações divergentes: por um lado, a imprensa apresentou essas dinâmicas de maneira laudatória como tentativas de "evitar a morte do xamanismo", "manter as tradições vivas" ou "salvar os conhecimentos tradicionais" do grupo; ${ }^{3}$ e, por outro lado, muitos Baniwa evangélicos as desaprovaram, argumentando não somente que iam contra as regras de vida cristãs, mas também que não eram conformes aos usos xamânicos ancestrais - denominados localmente "pajelança". ${ }^{4}$ Embora opostas, ambas as posturas se fundam numa mesma concepção essencialista do xamanismo, que pressupõe que essa formação religiosa constitui um conjunto fixo de saberes e práticas, suscetível de ser reproduzido de forma idêntica pelas gerações sucessivas.

Ora, a literatura antropológica relativa às terras baixas da América do Sul demonstrou nas últimas décadas o caráter dinâmico e a heterogeneidade

1 Agradeço a Izabella Bosisio pela revisão do manuscrito em português e a Milena Estorniolo pelos comentários estimulantes.

2 Os Baniwa formam no Brasil uma população de aproximadamente 6424 pessoas (Siasi/Sesai, 2013). Não existem estatísticas sobre as suas afiliações religiosas, mas estima-se que os evangélicos representam $80 \%$ do grupo (Wright, 2013, p. 5).

3 As três expressões provêm, respectivamente, de um artigo da Globo Amazônia (2010) intitulado "Aldeia indígena do Amazonas ganha escola de xamanismo", de um artigo do Instituto Socioambiental (ISA) (2008), uma ONG indigenista e ambientalista, intitulado "Inaugurada Escola de Xamã no Rio Aiari, na Terra Indígena Alto Rio Negro (AM)" e de um artigo do jornal A Crítica intitulado "Malikai Dapana: a escola de pajés", atualmente indisponível, mas uma versão foi publicada no website "Povos Indígenas no Brasil", do ISA, de onde foi consultada (Prazeres, 2010).

4 Se o termo "pajelança", de origem tupi, costuma ser associado às populações "caboclas" e remeter a um conjunto de práticas e representações inspiradas em diversos universos religiosos como as cosmologias e os rituais indígenas, o catolicismo, o kardecismo e os cultos afro-brasileiros (Langdon, 2013, p. 25; Maués, 1999, p. 198), no Alto Rio Negro, ele se refere de maneira mais estrita às cosmologias e usos rituais indígenas. Neste artigo, usarei a palavra nesse sentido, como um sinônimo da noção antropológica de "xamanismo". 
das práticas e representações xamânicas dessa área geográfica. Numa síntese sobre as formas - passadas e presentes - de xamanismo no Brasil e na Colômbia e sobre os modelos analíticos desenvolvidos pelos antropólogos para apreendê-las, Esther Jean Langdon salienta, por exemplo, a grande diversidade dos modos de formação, das técnicas e dos saberes dos xamãs, que possuem interesses e buscam alcançar objetivos distintos segundo os grupos, as épocas e os contextos políticos. Ressaltando seu papel de mediadores com a alteridade e a importância dos contatos interétnicos na construção dos seus conhecimentos e atividades, a autora propõe considerar o xamanismo antes de tudo como um fenômeno dialógico (Langdon, 2013, p. 31).

Neste artigo, abordarei as expressões do xamanismo baniwa partindo dessa ideia, ou seja, evitando vê-las como manifestações de uma suposta "tradição ancestral" ou, ao contrário, como fenômenos totalmente desconectados do antigo universo ritual do grupo, para focalizar-me nas relações e nos diálogos através dos quais se constroem. Após evocar brevemente as formas históricas de pajelança baniwa tais como foram descritas nas primeiras fontes etnográficas e as mudanças que sofreram durante a segunda metade do século XX devido à introdução do cristianismo evangélico na bacia do rio Içana, a região de origem dos Baniwa, me concentrarei nas suas expressões atuais. Examinarei mais precisamente duas iniciativas recentes de revitalização da pajelança: a criação de uma "Escola de Xamãs" e a realização de um documentário sobre a música baniwa incluindo cenas relativas a um ritual de iniciação. Através da análise das intervenções dos múltiplos atores que participaram desses projetos, buscarei entender os novos usos do xamanismo. Ao recorrer à noção de "patrimonialização", que ajuda a pensar os processos de revitalização cultural, tentarei mostrar que, após um largo tempo de marginalização, a pajelança baniwa está sendo reabilitada através de um diálogo entre certas famílias baniwa e certos "brancos" e que essas interações produzem seu "deslocamento" para uma nova esfera da vida social.

5 No Alto Rio Negro, o termo "branco" designa de forma genérica todos os não índios, independentemente da cor da sua pele. 


\section{Formas históricas de pajelança baniwa}

Povo indígena de língua arawak, os Baniwa estão estabelecidos no Alto Rio Negro, uma região pluriétnica do Amazonas, fronteiriça da Colômbia e da Venezuela. A maioria deles mora em "comunidades" ${ }^{6}$ localizadas no rio Içana, um afluente do rio Negro, mas desde os anos 1990 várias famílias também migraram para a capital regional, São Gabriel da Cachoeira. Em termos de organização social, o grupo é formado por vários sibs, agrupados por sua vez em fratrias, entre as quais as três mais importantes são os Walipere Dakenai, os Dzauinai e os Hohodene.?

Das formas de pajelança baniwa anteriores ao século XX muito pouco se sabe. As primeiras descrições etnográficas das práticas xamânicas desse grupo, esparsas em relatos de viagem de exploradores europeus, datam do início do século XX. ${ }^{8}$ Em 1909, o etnógrafo alemão Theodor Koch-Grünberg, que percorreu uma parte da bacia do rio Içana durante sua viagem ao Alto Rio Negro, forneceu informações sobre certas dessas práticas. Descreveu em particular danças cerimoniais (Koch-Grünberg, 2005, p. 110-114, 154-162), entre as quais algumas envolvem o uso de flautas sagradas chamadas "Kóai"9 (Koch-Grünberg, 2005, p. 207-211). Deixou também descrições vívidas de curas xamânicas

6 Introduzido pelos missionários católicos, para quem remetia inicialmente às Comunidades Eclesiais de Base, um modelo de organização social e religiosa definido pelo Concílio Vaticano II, o termo designa atualmente as aldeias indígenas em toda a região do Alto Rio Negro.

7 Retomo aqui a classificação de Wright (1998, p. 15). Convém assinalar, porém, que, se se admite geralmente que o grupo está formado de unidades exogâmicas e patrilineares, o número e a natureza dessas entidades sociais não estão claramente estabelecidos. Para uma discussão sobre o assunto, ver Xavier (2013, p. 81-119).

8 Referências mais sucintas à vida religiosa dos índios do Alto Rio Negro podem ser encontradas em escritos anteriores produzidos por missionários, militares ou representantes do governo. Para uma lista das principais fontes disponíveis sobre a região, ver Wright (2005, p. 298-315).

9 O nome Kóai (ou Kowai, Kuwai, etc.) remete a um herói cultural da cosmologia baniwa. Trata-se de uma figura complexa que, na mitologia do grupo, ensinou aos homens diversos conhecimentos e técnicas, mas que também deu origem ao "manhene", veneno ao qual se atribuem muitas doenças graves e mortes. A sua morte faz surgir as plantas que permitem fabricar as flautas usadas durante o rito de iniciação masculina. Tanto o rito quanto os instrumentos são assim chamados Kowai. São também conhecidos no Alto Rio Negro como "Jurupari" ou "Yurupari", nome que os primeiros missionários, que assimilavam o herói cultural a um demônio, lhes deram em nheengatu (língua geral). 
que sugerem que era comum entre os Baniwa recorrer a pajés de outros grupos para combater certos males (Koch-Grünberg, 2005, p. 114, 192).

Nos escritos do seu compatriota Curt Nimuendajú, que seguiu seus passos em 1927, as referências a aspetos religiosos são mais raras. O viajante menciona a presença de um "pajé" numa aldeia que visita e a existência de um culto comum a vários grupos da região, o “culto de Kóai-Yuruparí” (Nimuendajú, 1950, p. 139, 164).

Na primeira síntese sobre a "religião e o xamanismo" das populações indígenas do noroeste amazônico, publicada em 1948 no Handbook of South American Indians, Irving Goldman também evoca ideias e usos religiosos compartilhados por vários grupos, mais do que costumes particulares. Ressalta a importância de duas figuras cosmológicas, uma divindade suprema que mora no céu, possivelmente inspirada do deus cristão, e o herói cultural "Kúwai”. Faz menção a um culto dos antepassados que implica rituais com flautas sagradas cuja vista é formalmente proibida às mulheres; a uma mitologia sofisticada; e a um "complexo xamânico ricamente elaborado". Apresenta os xamãs, especialistas rituais que mobilizam diversas técnicas (uso de plantas medicinais, "aspiração" da doença com a boca, fumigação de tabaco, etc.), como indivíduos ambivalentes, a quem se atribui o poder de curar, bem como o de matar (Goldman, 1948, p. 793-798).

Em 1959, o estudo de Eduardo Galvão sobre a “aculturação indígena no Rio Negro" oferece também uma imagem abrangente da vida religiosa dos habitantes da região, mas inclui referências mais precisas à cosmologia e às práticas rituais dos Baniwa. O etnógrafo brasileiro cita, por exemplo, as principais figuras da mitologia do grupo, "Inapíri-kuri"10 - que, segundo ele, é frequentemente associado a Jesus Cristo - e seu filho "Kowái” (Galvão, 1959, p. 45-47). Descreve duas categorias de "grandes cerimônias tradicionais", o dabucurí, de caráter social-recreativo, e o ritual de Jurupari (nome nheengatu de Kowai), que implica entre outras coisas a prática da flagelação e o toque de flautas sagradas (Galvão, 1959, p. 48-49). Estabelece também uma distinção entre duas classes de xamãs, os "Maríris", considerados como mais poderosos, que realizam curas

10 Como no caso de Kowai, a grafia do nome dessa figura da cosmologia baniwa varia muito (Inapirikuli, Iapirikuri, Niãpirikoli, Ñapirikoli, Yaperikuli, etc.). Usarei aqui a grafia Yaperikuli, que me parece uma das mais simples. 
com canções acompanhadas do bater de um maracá e que usam paricáll para induzir o transe, e os "Dzuri", ${ }^{12}$ que curam com rezas e defumações de tabaco (Galvão, 1959, p. 51). No seu estudo, Galvão (1959, p. 52-55) assinala ainda a presença marginal de práticas de origem católica, as "festas de santo", no baixo Içana, e o sucesso, então recente, do protestantismo entre os Baniwa.

Os primeiros estudos sistemáticos sobre a vida religiosa dos Baniwa só aparecem no início dos anos 1980, com as publicações de Robin Wright, um antropólogo estadunidense que realizou várias pesquisas etnográficas com famílias baniwa. Apoiando-se nas narrativas de seus interlocutores indígenas e em fontes antigas (arquivos missionários e institucionais), Wright dedicou a maior parte da sua carreira à exploração das experiências religiosas, passadas e contemporâneas, dos Baniwa. Trabalhando principalmente entre as poucas famílias não convertidas ao cristianismo evangélico, estudou em detalhes as diferentes facetas do xamanismo. Interessou-se - entre muitos outros assuntos - pelos movimentos proféticos do final do século XIX e início do século XX, que eram liderados por poderosos xamãs que se apropriavam de certos símbolos cristãos (Wright, 2005; Wright; Hill, 1986); pela cosmologia e pelos rituais baniwa (Wright, 1998, 2013); pela ambivalência do xamanismo (Wright, 2004a); ou por sua relação com o cristianismo (Wright, 1999, 2009).

Essa atenção especial prestada às atividades e representações ligadas ao xamanismo coincide com um forte interesse pelo tema no campo dos estudos etnológicos amazonistas nas últimas décadas do século XX. No que diz respeito ao noroeste amazônico, vários trabalhos de referência sobre as expressões xamânicas são publicados na época, entre os quais podemos citar o estudo de Gerardo Reichel-Dolmatoff (1971) sobre o simbolismo dos índios tukano ou a análise de Stephen Hugh-Jones (1979) do rito Yurupari entre os Barasana.

Se não posso detalhar aqui as diversas abordagens desenvolvidas nesta abundante literatura dedicada ao xamanismo dos Baniwa e dos outros grupos indígenas do noroeste da Amazônia, quero destacar dois fatos importantes.

11 O paricá é um pó psicoativo inalado pelos pajés em contextos rituais feito a partir da casca de uma árvore (cf. Wright, 2013, p. 26).

12 Este nome designa uma figura da mitologia baniwa, irmão de Yaperikuli, xamã primordial e "dono" do tabaco. 
Em primeiro lugar, essas contribuições revelam que a pajelança baniwa não constitui uma formação religiosa radicalmente singular, que estaria isenta de componentes exteriores, pois não somente apresenta semelhanças com os outros sistemas xamânicos regionais mas também inclui referências ao universo católico. Convém precisar, contudo, que essa influência cristã não chega, na época, a dar à luz um sincretismo. Como especificam Wright e Hill (1986, p. 33) a propósito dos movimentos messiânicos, os líderes religiosos indígenas selecionavam símbolos cristãos que faziam sentido no contexto da sua experiência histórica e das culturas arawak regionais. Dito de outro modo, tratava-se de uma "assimilação" de elementos católicos pelo xamanismo, ou seja, de uma mudança que não afetava o sistema em profundidade..$^{13}$

Em segundo lugar, a pajelança tal como se desenvolveu antes da introdução do cristianismo evangélico na região do Içana não representa uma atividade separada das outras esferas da vida social: consiste em representações cosmológicas, um amplo corpus de narrativas mitológicas, saberes botânicos e ecológicos, ritos de passagem, rezas e danças, rituais de cura, etc., que saturam a maioria das dimensões da existência. Parece constituir, para retomar uma expressão usada por Jean-Pierre Chaumeil (1983, p. 318) na sua monografia sobre o xamanismo dos Yagua da Amazônia peruana, a "pedra angular" da sociedade. Wright (2004b, p. 380) a considera como uma "instituição" que, antes do movimento de conversão ao evangelismo, exercia uma "influência central em todas as aldeias".

A partir dos anos 1950, o xamanismo deixa, porém, de assumir esse papel central entre os Baniwa. Esse fenômeno está ligado à difusão do evangelismo na região do Içana, um processo desencadeado pela atuação de uma missionária estadunidense, Sophie Muller. Na seção seguinte, examinaremos as repercussões do proselitismo dessa mulher e dos seus discípulos nas práticas xamânicas baniwa.

13 Utilizo aqui o termo no sentido de Robbins, que considera a "assimilação" como um modelo de mudança cultural no qual "as pessoas são capazes de integrar [to fit] novas circunstâncias em velhas categorias", à diferença do que acontece na "transformação" ou na "adoção" (Robbins, 2004, p. 10-11, tradução minha). 


\section{A difusão do cristianismo evangélico e a marginalização da pajelança baniwa}

O episódio da evangelização das populações da bacia do Içana por Sophie Muller já está bastante bem documentado. Foi estudado primeiro por Wright (1999), que buscou compreendê-lo cruzando os pontos de vista dos seus diferentes protagonistas (Sophie Muller, os Baniwa e os missionários católicos, que tentaram impedir a propagação da nova fé, considerada por eles como uma "heresia"), e por vários outros autores que discutiram e enriqueceram depois os aportes do antropólogo norte-americano. ${ }^{14} \mathrm{Na}$ base desses trabalhos, podemos afirmar que o sucesso do cristianismo evangélico entre os Baniwa se deve a vários fatores.

O movimento de conversão pode ser visto em primeiro lugar como uma reação à opressão do regime extrativista. ${ }^{15} \mathrm{Na}$ época da vinda de Sophie Muller, muitos índios estavam submetidos a patrões brancos que exploravam seu trabalho para comercializar produtos florestais. Ora, a missionária incentivava-os a libertarem-se desses laços de dependência e a voltarem a viver em comunidade longe do mundo dos brancos, assegurando que Deus garantiria seu sustento se seguissem suas instruções. Nesse contexto, o caminho da conversão foi percebido em larga medida como uma saída a essa situação de crise. Em segundo lugar, o entusiasmo dos habitantes do Içana pela "palavra de Deus" está fortemente ligado à sua curiosidade pela Bíblia e pela linguagem escrita, que eram consideradas como a "chave do conhecimento dos brancos" (Wright, 1999, p. 188). Ao alfabetizar seus discípulos e ao ensinar-lhes a decifrar o livro sagrado, a missionária dava-lhes acesso a um saber considerado como valioso. Segundo Wright (1999, p. 198, 206), a receptividade dos Baniwa à mensagem de Sophie Muller, uma mulher peculiar que era estrangeira mas falava as línguas indígenas, deve-se também à possível assimilação da missionária às figuras messiânicas do início do século. Outros aspectos poderiam ser mencionados, mas o que podemos ressaltar é que o cristianismo evangélico não foi imposto

14 Para uma síntese das interpretações antropológicas do sucesso da atuação de Sophie Muller entre os Baniwa e grupos vizinhos, cf. Capredon (2016, p. 158-170).

15 A exploração da mão de obra indígena para a "extração" de produtos florestais existe desde a época colonial, mas intensifica-se do final do século XIX até meados do século XX devido ao boom da borracha. 
à força aos Baniwa: dadas as circunstâncias históricas, os argumentos de Sophie Muller pareciam convincentes para seus interlocutores. Muitos habitantes do Içana acabaram então renunciando aos seus costumes para adotar as regras de comportamento e os usos promovidos pela missionária.

Ora, as principais mudanças exigidas por Sophie Muller eram relativas à pajelança. A pregadora, que, como muitos outros missionários (católicos ou protestantes), associava as atividades rituais indígenas a cultos demoníacos, condenou tudo o que estava relacionado com o xamanismo. Diabolizou as figuras da cosmologia baniwa, ordenou aos xamãs que jogassem seus instrumentos no rio, proibiu as festas de troca (dabucuri ou podáali ${ }^{16}$ ) e os rituais, e interditou o tabaco e o paricá - duas substâncias usadas pelos pajés. Conseguiu também impedir o consumo de bebidas alcoólicas, em particular do caxiri (bebida de mandioca fermentada), um componente indispensável das festividades indígenas regionais.

Perante esta ofensiva, a pajelança perdeu pouco a pouco terreno. Muitos especialistas rituais abandonaram suas funções, e tanto os podáali quanto os ritos, como o ritual Kowai de iniciação masculina, foram substituídos por cerimônias evangélicas, as "Santas Ceias" e "Conferências".

Essa expansão do movimento evangélico não foi, contudo, fluida, pois encontrou alguns obstáculos. Nos anos que seguiram a vinda da missionária americana, surgiram conflitos entre os evangélicos e os não convertidos, genericamente denominados "católicos". ${ }^{17}$ Os crentes difamaram os pajés, proibiram o acesso de seus templos aos não batizados ou recusaram compartilhar sua comida com eles (Wright, 1999, p. 201-202). Essas disputas, que se sobrepunham geralmente a tensões preexistentes entre comunidades, sibs ou fratrias, ocasionaram o afastamento ou até o deslocamento das famílias que não aderiam ao movimento majoritário na sua aldeia.

16 O termo dabucuri, que vem da língua geral (nheengatu), é o mais comum no Alto Rio Negro, mas em baniwa as festas de troca indígena são chamadas de podáali.

17 No Alto Rio Negro, o termo "católico" pode remeter a uma vasta gama de posicionamentos religiosos. Em função dos contextos discursivos, pode designar pessoas que frequentam a Igreja Católica; adeptos de um catolicismo "popular" cujas principais manifestações são as festas de santos; mas também, de forma genérica, todos os não crentes, inclusive as pessoas que mantêm práticas xamânicas. 
A rejeição ou, em certos casos, a adesão parcial à "palavra de Deus" de alguns membros do grupo abriu espaço para a perpetuação da pajelança em contextos determinados. Por um lado, algumas famílias que resistiram desde o início à penetração da nova religião continuaram a cultivar saberes e - no caso de alguns homens - práticas xamânicas. Essas famílias pertencem geralmente à fratria hohodene, cujos representantes ocupam tradicionalmente o rio Aiari, um afluente do Içana. Segundo Wright (1999, p. 199), no momento da chegada de Sophie Muller, a presença de poderosos pajés nessa zona conteve o avanço do movimento evangélico. Desde então, as comunidades dessas famílias, situadas a montante do rio Aiari, representam o bastião da pajelança baniwa.

Por outro lado, existe um componente da pajelança que se manteve em muitas comunidades, inclusive nas aldeias evangélicas: a sua dimensão terapêutica. Mais precisamente, trata-se dos saberes e usos de uma categoria de xamãs, os que Galvão (1959) chamava de "Dzuri", mais conhecidos em português como "benzedores". Considerados como menos poderosos que os pajés, os benzedores praticam curas recorrendo à recitação de fórmulas, ao uso de plantas medicinais e a fumigações de tabaco. A persistência desse tipo de atividade entre a maioria dos membros do grupo deve-se provavelmente à grande discrição desses especialistas rituais. De fato, os benzedores, que tendem a minimizar os seus conhecimentos afirmando que curam só "as doenças que não são muito graves", costumam realizar sessões terapêuticas apenas para seus parentes próximos, no espaço doméstico. Invisíveis ou pouco problemáticas para as autoridades evangélicas, são toleradas em muitos lugares. No final dos anos 1990, certos evangélicos chegaram até a apoiar um projeto de revitalização da "medicina tradicional" que implicava o registro de saberes detidos por benzedores, como o conhecimento dos remédios fitoterápicos ou a taxonomia indígena das doenças, estreitamente ligada à antiga cosmologia do grupo (Garnelo, 2002).

Cabe mencionar também que o benzimento segue sendo uma prática relativamente comum entre os Baniwa que deixaram a região do Içana para estabelecer-se na capital do Alto Rio Negro, São Gabriel da Cachoeira. Os Baniwa começaram a migrar para a cidade nos anos 1990 por diversos motivos, entre os quais podemos citar a busca de empregos remunerados, a vontade de ter um melhor acesso à educação escolar e aos serviços de saúde, ou também conflitos nas suas comunidades de origem. Entre as famílias instaladas em São Gabriel 
e em comunidades periurbanas, não é raro recorrer ao benzimento para enfrentar os infortúnios da vida cotidiana.

Além do xamanismo praticado por pajés provenientes de famílias "católicas", persiste assim uma pajelança difusa na esfera doméstica, que está centrada na cura e na resolução de pequenos males. Como sugere um comentário de Chaumeil (1983, p. 319, tradução minha), que afirma que entre os Yagua da Amazônia peruana "a profissão [de xamã] chega a reduzir-se à sua única dimensão terapêutica" nas zonas de forte contato com os brancos, esse fenômeno parece bastante frequente nos contextos de intensificação das relações com a sociedade nacional.

A difusão do cristianismo evangélico na região do Içana não causou, assim, o desaparecimento do xamanismo, mas provocou a desqualificação dos pajés nas aldeias baniwa, onde só se toleram certas práticas terapêuticas discretas que não interferem no modelo religioso dominante, e a marginalização daqueles que mantiveram suas atividades no rio Aiari. Em 2004, Wright afirmava que o xamanismo baniwa estava em "franca decadência", pois contabilizava só sete pajés ativos do lado brasileiro da fronteira - todos no rio Aiari. Precisava, porém, que "ainda são vivos em todas as aldeias [...] os conhecimentos dos mitos e das rezas de cura e plantas medicinais" (Wright, 2004b, p. 380).

Poucos anos mais tarde, esse declínio foi revertido por novas dinâmicas, chamadas no Alto Rio Negro de "projetos de revitalização cultural". No Aiari e na periferia de São Gabriel da Cachoeira, surgiram iniciativas destinadas a reabilitar conhecimentos tradicionais, especialmente saberes associados à pajelança. Como veremos adiante, esses processos não representaram uma simples volta aos antigos usos xamânicos. As suas próprias denominações - "projeto", "escola", "documentário" - oriundas do léxico português, sugerem uma reformulação notável das atividades xamânicas. A seguir, examinarei o contexto em que nasceram tais iniciativas, descreverei seu desenvolvimento e tentarei entender o que estava em jogo para seus instigadores.

\section{Os projetos de revitalização da pajelança baniwa}

No Alto Rio Negro, o desenvolvimento dos projetos de revitalização cultural corresponde à segunda etapa do movimento indígena regional. Entendo aqui por "movimento indígena" o conjunto de ações políticas impulsionadas desde 
os anos 1970 pelos índios da região para reivindicar seus direitos na sociedade brasileira. Esse movimento, que se insere num processo mais amplo de mobilizações indígenas no cenário nacional e internacional, visava inicialmente a defesa de direitos territoriais. Depois das associações indígenas - agrupadas na poderosa Federação das Organizações Indígenas do Rio Negro (Foirn) - conseguirem a homologação de uma extensa Terra Indígena em 1998, as reivindicações foram ampliadas a outras áreas como a educação, a saúde e, sobretudo, a cultura. O interesse por este último tema, que foi incentivado por indigenistas e antropólogos, surgiu num contexto de preocupação crescente pela preservação das "culturas tradicionais"18 a nível internacional (Lima Filho; Abreu, 2010, p. 145-147).

Entre os Baniwa, foram principalmente famílias Hohodene que se apropriaram do assunto, pois a temática era mais problemática para os evangélicos, entre os quais muitos associam a "cultura" a costumes antigos incompatíveis com a sua afiliação religiosa. Para ser mais precisa, os evangélicos envolveram-se também em iniciativas de revitalização cultural, mas concentrando-se em aspectos materiais e econômicos que não iam contra os seus princípios religiosos. Nos anos 2000 , elaboraram, por exemplo, um projeto denominado "Arte Baniwa", destinado a valorizar uma atividade artesanal local, a cestaria, a fim de gerar renda para as comunidades do Içana através da comercialização de objetos em fibra de arumã (Wright, 2009).

Em contrapartida, as famílias "católicas" viram no interesse crescente dos brancos pelas "culturas" indígenas ${ }^{19}$ uma oportunidade de reabilitar as práticas e os conhecimentos ligados à pajelança e de reconquistar prestígio no cenário político regional. Entre as iniciativas que desenvolveram, examinarei dois projetos: a "Escola de Xamãs", fundada pela família de Mandu, um velho Hohodene

18 Categoria da Unesco (1989, p. 248, tradução minha) definida como um "conjunto de criações que emanam de uma comunidade cultural fundada na tradição, expressas por um grupo ou por indivíduos e que reconhecidamente respondem às expectativas da comunidade enquanto expressão de sua identidade cultural e social; as normas e os valores se transmitem oralmente, por imitação ou de outras maneiras. Suas formas compreendem, entre outras, as línguas, a literatura, a música, a dança, os jogos, a mitologia, os rituais, o artesanato, a arquitetura e outras artes."

19 Reconstituir a emergência desse fenômeno é uma tarefa que ultrapassa os limites deste estudo, mas podemos citar alguns fatores identificados por Chaumeil num artigo sobre o "comércio da cultura" entre os povos indígenas amazônicos. O autor relaciona os processos de revitalização cultural ao desenvolvimento da indústria turística, a uma nova paixão ocidental pela "arte primitiva", ou também à ratificação em 2003 da Convenção da Unesco sobre a proteção do patrimônio imaterial (Chaumeil, 2009). 
considerado como um dos últimos pajés baniwa; e o documentário Podáali, valorização da música baniwa, realizado pela família de Luiz, o líder - também Hohodene - de uma comunidade periurbana. Escolhi esses projetos porque consegui recolher mais dados etnográficos sobre eles que sobre outros: ${ }^{20}$ no caso da Escola de Xamãs, apoiei-me em descrições de Wright (2013, p. 315-324), artigos da imprensa regional e entrevistas que efetuei com Mandu e dois dos seus filhos, Alberto e Ercília. No caso do filme Podáali, acompanhei a implementação de algumas etapas do projeto durante meu trabalho de campo, ${ }^{21}$ tive acesso depois a arquivos administrativos e completei esse material com um relato etnográfico redigido por outra antropóloga (Montardo, 2011).

\section{A Escola de Xamãs}

Manuel da Silva, mais conhecido como Mandu, nasceu por volta de 1920 e tornou-se pajé na sua juventude, após uma longa aprendizagem junto a dois mestres. ${ }^{22}$ Durante muitos anos, esse homem Hohodene foi também capitão ${ }^{23}$ da sua aldeia situada no rio Aiari, Uaupuí Cachoeira. Já marginalizada pela difusão do movimento evangélico no Içana, essa comunidade perdeu ainda mais influência com o desenvolvimento do movimento indígena regional, pois os líderes que ascenderam aos mais altos cargos nas associações políticas baniwa pertenciam à fratria walipere dakenai (Garnelo, 2002, p. 265-272). No final

20 Não foram muitas as iniciativas desse tipo entre os Baniwa, mas houve pelo menos duas mais: a criação de uma "Casa de Adornos" destinada à revitalização das danças indígenas e em particular das danças ligadas ao ritual de iniciação masculina em outra comunidade do rio Aiari (Wright, 2013, p. 309-315) e, após o "fechamento" da Escola de Xamãs, uma tentativa de dar continuidade a esse projeto por um genro de Mandu, que criou um lugar similar, batizado "Casa de Keruaminali” em referência aos antepassados dos Hohodene (Wright, comunicação pessoal, correio eletrônico, 15 nov. 2016).

21 Realizei entre 2008 e 2011 três pesquisas etnográficas no Alto Rio Negro que, cumuladas, representam 17 meses de trabalho de campo. Trabalhei principalmente com os Baniwa estabelecidos na cidade de São Gabriel da Cachoeira e em comunidades periurbanas.

22 Para uma biografia de Mandu, reconstituída com a ajuda da sua filha Ercília, ver Wright (2013, p. 34-52).

23 A palavra designa no Alto Rio Negro os líderes das aldeias indígenas. Os capitães, cujo perfil se aproxima do tipo ideal do chefe ameríndio elaborado por Pierre Clastres (2011), não possuem o poder de comandar. Incentivam e organizam as atividades coletivas, assumem um papel de mediador em caso de conflito e representam a comunidade em meio aos interlocutores de fora, em particular os brancos, mas sem impor a sua vontade. 
dos anos 1990, esses líderes evangélicos empreenderam vários projetos com o apoio da Foirn e do Instituto Socioambiental (ISA), uma ONG ambientalista e indigenista: os já citados projetos de medicina tradicional e de cestaria e a fundação de uma escola indígena que, em pouco tempo, se tornou um estabelecimento inovador e próspero. Sentindo-se excluídos dessas iniciativas, que permitiam a seus vizinhos beneficiarem-se de financiamentos, material pedagógico, computadores e outras vantagens, os Hohodene decidiram criar seu próprio projeto.

No início dos anos 2000, Alberto e Ercília formularam um plano de revitalização da "cultura dos Baniwa do rio Aiari", inspirando-se em projetos de "medicina tradicional" desenvolvidos por grupos indígenas do Uaupés (Wright, 2013, p. 316). Os seus principais objetivos eram então revitalizar "as tradições do xamanismo e os rituais de iniciação (com seus cantos especializados), bem como o uso de remédios com plantas", produzir livros para as escolas e construir uma maloca ${ }^{24}$ que serviria de biblioteca e centro cultural. De maneira mais geral, tratava-se de mobilizar os "conhecimentos tradicionais" para elaborar "respostas sustentáveis" a "problemas de saúde, perda das tradições, problemas ligados à migração e redução da população indígena que levam estas comunidades a estarem cada vez mais dependentes" - frases extraídas do projeto (cf. Wright, 2013, p. 316-318, tradução minha).

Para alcançar esses objetivos, Alberto solicitou o apoio do ISA, de uma ONG sanitária, Saúde sem Limites, e da Foirn, mas as organizações recusaram-se, segundo ele, a ajudá-lo. O filho do xamã atribuiu a falta de interesse dos seus interlocutores à hostilidade dos evangélicos - que têm parcerias com essas organizações ou ocupam cargos importantes nelas - em relação à pajelança:

As pessoas também não gostaram desse negócio de pajelança, né, a maioria [delas] pra cá pra cima no Içana, Aiari, Cuiari são evangélicas, que já abandonaram totalmente essa pajelança. Aí elas não gostaram, por isso não me associei com essas pessoas da Foirn, eu estava buscando meu direito próprio, com minha família mesmo.

24 No Alto Rio Negro, o termo designa as grandes habitações coletivas indígenas, que antigamente abrigavam várias famílias. Essas construções com teto de folhas de palmeiras eram ao mesmo tempo espaços de vivência e espaços cerimoniais. Foram abandonados durante o século XX sob a influência dos missionários, que promoviam a construção de casas separadas. Entretanto, várias malocas foram reconstruídas nas últimas décadas no contexto de projetos de revitalização cultural. São geralmente destinadas a receber eventos políticos e festivos. 
Mas Alberto também menciona mais humildemente seu desconhecimento das modalidades administrativas requeridas para elaborar e implementar um projeto:

Como falei não tem assim outras pessoas que querem me apoiar. Eu já fui no ISA, eu já fui aqui na Foirn, só que as pessoas não estão de acordo com o projeto. Também eu não sei fazer assim projeto bem feito, porque eu nunca peguei uma oficina para montar projetos.

A elaboração de "projetos", no sentido de documentos escritos constituídos para obter financiamentos de instituições permitindo concretizar objetivos predefinidos, representa de fato um verdadeiro desafio para os moradores das comunidades. Nesse contexto, os Hohodene optaram por recorrer ao antropólogo Robin Wright, que trabalha com eles há muito tempo no âmbito das suas pesquisas etnográficas. O pesquisador estadunidense solicitou, por sua vez, uma associação californiana, a Foundation for Shamanic Studies (FSS). Criada em 1979 por Michael Harner, um antropólogo que se afastou do mundo acadêmico para dedicar-se plenamente à prática e à defesa do xamanismo, a FSS ambiciona preservar os "xamanismos tradicionais" em diferentes regiões do mundo e promover o "core-shamanism", uma síntese de diferentes formas de xamanismo elaborada para um público ocidental. Interessados pela iniciativa dos Hohodene, seus representantes aceitaram imediatamente financiá-la. Além disso, atribuíram a Mandu o prêmio de "Tesouro Vivo", que lhe dava acesso a uma pequena pensão anual (Wright, 2013, p. 319).

Através do diálogo que se instaurou - pela intermediação de Robin Wright entre os Hohodene e seus inesperados aliados norte-americanos, o projeto, que comportava inicialmente várias dimensões, foi recentrado na questão da transmissão dos conhecimentos xamânicos. Os Hohodene acabaram criando um lugar de ensino da pajelança batizado Malikai Dapana, o que significa em baniwa "Casa do Saber e Poder Xamânico" (Wright, 2013, p. 319). Inspirada na arquitetura das malocas, a casa, mais conhecida em português sob o nome de "Escola de Xamãs" ou "Escola de Pajelança", foi inaugurada em 2009, em presença de uma pequena delegação de autoridades brancas na qual se encontravam Robin Wright e o presidente da Funai. A cerimônia de inauguração incluiu apresentações de danças "tradicionais", distribuição de caxiri, troca 
de presentes, e culminou com a entrada em cena de Mandu e seus 12 aprendizes, que, após exibirem seus instrumentos e inalarem paricá, entoaram cantos xamânicos (Wright, 2013, p. 319-324). Os esforços conjuntos dos Hohodene e do antropólogo pareciam então coroados de sucesso.

Porém, o projeto não tardou em periclitar. Segundo Alberto, nenhum jovem das outras comunidades veio se juntar ao grupo de aprendizes, formado principalmente pelos netos de Mandu, e a saúde enfraquecida do velho xamã impedia organizar uma formação eficaz. Também resultou difícil combinar o modelo da "escola", que implicava uma planificação do ensino e a democratização do saber xamânico, com as antigas modalidades de iniciação à pajelança, que não seguiam horários estritos, que tendiam a excluir as mulheres, e que requeriam um ascetismo rigoroso (dieta especial, abstinência sexual, isolamento, etc.). Ainda por cima, um drama familial levou na época os Hohodene a deixarem provisoriamente a comunidade de Uaupuí Cachoeira para instalar-se na cidade, em São Gabriel da Cachoeira - onde possuem uma casa desde o final dos anos 1990. Mas o fator decisivo, que, segundo Alberto, conduziu a sua família a desistir do projeto, foi o esgotamento do financiamento. Sem a ajuda da FSS, que, depois do lançamento do projeto, reduziu seu apoio financeiro à pequena verba mandada anualmente a Mandu, o filho do xamã julgou que não era possível manter as atividades de Malikai Dapana.

Em 2011, quando conheci os Hohodene em São Gabriel da Cachoeira, o projeto estava então em suspenso. Alberto evocava a possibilidade de implantar uma escola de pajelança na zona urbana, enquanto Ercília expressava o desejo de construir uma espécie de centro de saúde onde contrataria benzedores e pajés para oferecer consultas xamânicas aos habitantes da cidade. Perguntaram-me se podia ajudá-los a financiar esses novos projetos ou a encontrar instituições provedoras de fundos no meu país para fazê-lo.

O projeto Malikai Dapana não possibilitou assim a reabilitação da pajelança ao nível do grupo baniwa, mas teve outros resultados. Primeiro, os Hohodene de Uaupuí Cachoeira, que se queixavam frequentemente de não serem contemplados na distribuição dos recursos institucionais atribuídos aos Baniwa, conseguiram, pelo menos pontualmente, apoio econômico; e segundo, essa família oriunda de uma comunidade remota do rio Aiari ganhou notoriedade no exterior da bacia do Içana. Depois da inauguração da Escola de Xamãs, vários artigos saíram na imprensa regional, e a FSS publicou no seu website oficial, 
em inglês, uma descrição do projeto e um retrato de Mandu, ${ }^{25}$ junto a biografias de xamãs de outras regiões do mundo (Sibéria, Nepal, Tibete, Colômbia, etc.) que receberam o prêmio de Tesouro Vivo. Com isso, o velho pajé conseguiu chamar a atenção de certas categorias de brancos (antropólogos, jornalistas, mas também brancos "da região", que chegam a pedir consultas para ele) que lhe oferecem o reconhecimento que não tinha no seu grupo.

\section{O documentário Podáali e a revitalização do ritual Kowai}

Batizado Podáali, valorização da música baniwa, o segundo projeto de revitalização cultural nasceu sob o impulso dos membros de outra família Hohodene, Luiz, Luzia e seus filhos, que, no início dos anos 1990, deixaram o rio Aiari para fundar uma aldeia na periferia de São Gabriel da Cachoeira. Com o tempo, famílias de outros grupos indígenas agregaram-se a esse "núcleo" baniwa dando à luz uma comunidade pluriétnica, Itacoatiara-Mirim.

A partir dos anos 2000, os Baniwa começaram a estabelecer parcerias com o ISA, a Foirn e outras instituições regionais para desenvolver atividades suscetíveis de melhorar as suas condições de vida. Após tentar sem muito sucesso implementar projetos de artesanato, de piscicultura e de apicultura, seguiram o caminho da revitalização cultural optando por revalorizar as práticas cerimoniais do podáali, especialmente as danças indígenas. Decidiram enfatizar a música e as danças porque o pai de Luiz possuía um conhecimento aprofundado do repertório musical e das coreografias baniwa. Tratava-se de reabilitar essas competências e de torná-las mais conhecidas através de um documentário.

Em primeiro lugar, os Hohodene construíram uma grande maloca a fim de dispor de um espaço adequado para receber visitantes e realizar os podáali. Graças ao apoio do ISA e da Foirn, conseguiram financiamentos exteriores e começaram a erguer o imponente edifício. Mas os recursos não eram suficientes para terminar a obra e implementar a segunda parte da iniciativa, a realização do filme. Pediram então a ajuda de um líder baniwa da Foirn, que contatou uma antropóloga especialista da área do Içana, a qual solicitou, por sua vez, uma colega etnomusicóloga, Deise Montardo. Essa pesquisadora

25 A descrição do projeto e o retrato de Mandu encontram-se na seção "Indigenous Assistance" do website, respectivamente em Baniwa... (2009) e em Living... ([s.d]). 
entusiasmou-se com o projeto e propôs submetê-lo a um edital da Petrobras para conseguir ajuda financeira. Isso pode parecer surpreendente, mas na época a companhia petrolífera desenvolvia um programa de financiamento do patrimônio imaterial brasileiro. Como no caso dos Hohodene de Uaupuí Cachoeira, a etnomusicóloga adaptou o projeto inicial da família de Luiz para que correspondesse aos critérios de seleção da empresa: estabeleceu um calendário, identificou os protagonistas do projeto e descreveu seus principais objetivos. A candidatura foi aprovada, e os Hohodene receberam um primeiro financiamento. Como possuíam um dossiê escrito completo, aproveitaram para mandá-lo a outro edital, dessa vez do Ministério da Cultura, em que foi mais uma vez premiado e recebeu recursos adicionais. Com isso, os Baniwa de Itacoatiara-Mirim podiam começar a realização do documentário. Solicitaram, então, como já tinham feito para a construção da maloca, a ajuda de profissionais, o que provocou uma nova ampliação da equipe envolvida na iniciativa.

No auge do projeto, quando se concretizou a gravação do filme, a equipe do Podáali chegou a contar com dezenas de integrantes: os habitantes da comunidade de Itacoatiara-Mirim, entre os quais se destacavam Luiz, coordenador do projeto e "Maadzero" (mestre de cerimônia) da maloca, e um dos seus filhos, Moisés, vice-coordenador; e os participantes exteriores, que eram na sua maioria "brancos de fora", ou seja, pessoas oriundas de outras regiões do Brasil - três membros do ISA; um arquiteto que ajudou a desenhar a estrutura da maloca; a etnomusicóloga Deise Montardo, uma estudante em antropologia que efetuou uma pesquisa sobre o repertório coreográfico baniwa; dois cineastas e um fotógrafo profissional; aos quais podemos acrescentar lideranças indígenas e outros antropólogos, que colaboraram mais esporadicamente.

O projeto Podáali foi então elaborado, formulado, debatido, modificado, reformulado e, pouco a pouco, definido através do diálogo entre esses diversos atores, indígenas e não indígenas, da região e "de fora”. Além da construção da maloca, batizada "Casa de Conhecimento", e da filmagem das danças e atividades ligadas aos podáali, foi decidido organizar uma expedição ao Aiari a fim de recuperar um conjunto de flautas sagradas que os Hohodene tinham deixado submersas ${ }^{26}$ ali quando migraram para a periferia urbana. A ideia era voltar a realizar um ritual

26 Quando não são usadas, as flautas Kowai estão guardadas debaixo da água, submersas em algum rio ou igarapé para que ninguém possa vê-las e para preservar as suas qualidades musicais. 
de iniciação masculina, o ritual Kowai, com os instrumentos, e registrá-lo no filme, cujo roteiro foi progressivamente estruturado ao redor do evento.

Nessa perspectiva, uma parte da equipe viajou para o rio Aiari em outubro de 2010. Com a ajuda de habitantes de comunidades vizinhas, construíram um barracão com teto de folhas de palmeira e encenaram algumas sequências do ritual Kowai: oferta de frutas do mato, danças masculinas conduzidas por um velho pajé de uma aldeia próxima, sessão de flagelação realizada com os adabí (chicotes indígenas), durante a qual os participantes devem demostrar sua resistência à dor, e, ápice da cerimônia, o toque das flautas. Durante todo o processo, a interdição de ver os instrumentos sagrados foi estritamente respeitada: quando os homens chegaram com os aerófonos, as mulheres, as crianças e os homens não iniciados correram para esconder-se no mato (Montardo, 2011, p. 9), e, no momento de filmar, as câmeras foram dirigidas para uma lona que escondia os instrumentos. Porém, segundo Luiz, o ritual não foi organizado de forma correta, porque a viagem foi feita muito em cima da hora (Montardo, 2011, p. 9). Mais tarde o líder Hohodene disse-me que só tinha feito "um pouco" do ritual porque não tinha participantes suficientes.

Apesar disso, os habitantes da comunidade de Itacoatiara-Mirim ficaram bastante satisfeitos com os resultados do projeto. Se os jovens não foram plenamente iniciados aos conhecimentos e valores "tradicionais" nem mudaram de estatuto social, foram em contrapartida "iniciados" à linguagem cinematográfica e ao manuseio de um material audiovisual sofisticado. Receberam aulas de cinema na maloca, filmaram eles mesmos as sequências do documentário e editaram um vídeo de 30 minutos, que foi traduzido em várias línguas (português, inglês e francês) e comercializado sob a forma de DVDs. Além disso, os moradores da aldeia criaram durante o projeto a Associação Cultural Indígena Casa de Conhecimento (ACICC), que lhes permitiu ganhar visibilidade política num contexto em que as comunidades periurbanas, situadas fora da Terra Indígena, recebem pouca atenção das organizações indígenas e indigenistas. De maneira mais geral, o projeto levou a comunidade a ampliar consideravelmente a sua rede de aliados, como no caso dos Hohodene de Uaupuí Cachoeira. Os podáali realizados na maloca atraíram, por exemplo, autoridades municipais entre as quais algumas que contrataram depois os Baniwa para fazerem apresentações de danças indígenas em eventos regionais, bem como visitantes famosos, como o antropólogo Eduardo Viveiros de Castro, que deu uma oficina 
de sensibilização à questão dos direitos autorais na maloca, o músico e antigo ministro da cultura Gilberto Gil, que visitou a comunidade em busca de inspiração musical, ou, ainda, o chefe de reputação internacional, Alex Atala, curioso da gastronomia indígena. A aldeia de Itacoatiara-Mirim passou, assim, a ser uma espécie de laboratório de revitalização da cultura baniwa na zona periurbana.

O projeto não permitiu alcançar realmente a prosperidade desejada, mas ofereceu novas oportunidades econômicas para os Baniwa e conferiu-lhes uma visibilidade que facilitou a implementação de políticas públicas na aldeia. Pouco tempo depois da finalização do projeto, os moradores de Itacoatiara-Mirim conseguiram, por exemplo, uma ajuda da prefeitura para construir casas de alvenaria que pediam desde muito tempo. Os dois jovens que mais se envolveram na gravação do filme, Moisés e Paulinho, também criaram uma pequena empresa de produção de filme, Vídeo de Maloca Produções, para transmitir os conhecimentos adquiridos durante o projeto a outros jovens e para tentar realizar um longa-metragem. Estão desde esse momento à procura de financiadores para concretizar essas novas iniciativas.

Em suma, o projeto Podáali tampouco teve muito êxito no que diz respeito à revitalização dos saberes e das práticas ligados à pajelança dentro do grupo baniwa, mas representou um sucesso importante na área das "relações exteriores" da comunidade de Itacoatiara-Mirim. Permitiu a seus membros despertar o interesse de instituições e de atores "de fora", captar recursos exteriores e ganhar prestígio.

\section{De instituição social a ferramenta diplomática: a patrimonialização da pajelança baniwa}

A descrição desses projetos mostra claramente que as iniciativas de revitalização da pajelança não levam à reprodução exata das antigas práticas xamânicas, nem, tampouco, a uma ruptura total com elas. As limitações impostas pela maioria evangélica, que segue sendo reticente à reabilitação das atividades xamânicas, conjugadas às novas oportunidades que surgem através das relações com um público branco curioso do xamanismo, ocasionam uma reconfiguração do lugar da pajelança na sociedade baniwa e uma redefinição dos seus usos. Para apreender melhor esses fenômenos, mobilizarei a noção 
de patrimonialização, que pode iluminar certos aspectos dos projetos de revitalização cultural dos Baniwa.

A categoria de "patrimônio" tornou-se um tema de debates nacionais e internacionais durante a segunda metade do século XX devido a várias circunstâncias, especialmente à atuação da Organização das Nações Unidas para a educação, a ciência e a cultura (Unesco) (Lima Filho; Abreu, 2010, p. 142-145). No início, a abordagem do patrimônio por essa organização internacional, enraizada numa perspectiva acadêmica ocidental, "estava limitada às categorias tradicionais da história da arte 'clássica' e moldada pelos princípios museológicos ocidentais" (Bortolotto, 2007, p. 22, tradução minha). A partir dos anos 1990, a Unesco passou a desenvolver uma nova política de salvaguarda cultural menos centrada em "objetos" e mais atenta a "processos vivos" (como tradições orais, conhecimentos, rituais, eventos festivos, etc.) (Bortolotto, 2007, p. 22), uma proposta que foi bem acolhida no Brasil (Lima Filho; Abreu, 2010, p. 147). Como assinala Bortolotto (2011, p. 21-22), essa ampliação da noção de patrimônio a expressões culturais imateriais - que se concretizou pela adoção da categoria de "patrimônio cultural imaterial" primeiro na Unesco e logo em instituições culturais nacionais - foi suspeita no campo antropológico de favorecer a museificação das culturas. Os estudos que acompanharam os fenômenos de patrimonialização revelaram, porém, processos bem mais complexos, que não se reduzem à imposição de políticas patrimoniais pelas instituições, mas que envolvem a participação ativa de grupos locais na definição, criação ou, às vezes, contestação do que deve ser patrimonializado.

Na introdução de um número de revista dedicado aos usos patrimoniais dissidentes, Julien Bondaz, Cyril Isnart e Anaïs Leblon (2012, p. 10, tradução minha) ressaltam, por exemplo, que a produção do patrimônio não é mais uma prerrogativa dos Estados, mas uma atividade à qual participam numerosos atores:

Desde várias décadas já, as coletividades territoriais, ${ }^{27}$ os produtores agrícolas, os comitês de turismo, os atores dos territórios fronteiriços, as comunidades transnacionais e certos [atores] da mídia se transformam em empresários culturais

27 Na França e em outros países francófonos, as "coletividades territoriais" incluem os municípios, departamentos e regiões. Designam estruturas jurídicas que exercem poderes administrativos delegados pelo Estado em territórios determinados num contexto de descentralização do poder. 
suscetíveis de propor por si mesmos conteúdos culturais ou de contestar as suas versões oficiais.

Podemos acrescentar a isso que esses atores variados intervêm em distintas escalas: na escala local, regional, nacional e também internacional.

No caso dos Baniwa, podemos observar que os projetos de revitalização cultural também emergem numa vasta "arena patrimonial" (Bondaz; Isnart; Leblon, 2012) composta por atores muito diversos: ao nível local, temos pequenas comunidades indígenas ${ }^{28}$ cujos membros aspiram a revalorizar costumes reprimidos durante muito tempo e a melhorar suas condições de vida; e ao nível nacional e transnacional, organismos como o Ministério da Cultura, a empresa Petrobras e a ONG estadunidense Foundation for Shamanic Studies (FSS), que disponibilizam fundos para a preservação de patrimônios culturais nacionais ou transnacionais. ${ }^{29}$ Entre os dois, uma profusão de atores intermediários atuam ao nível regional tecendo conexões entre as aldeias indígenas e as instituições. São líderes indígenas que trabalham na Foirn, indigenistas e técnicos do ISA, representantes das instituições municipais, pesquisadores oriundos das grandes cidades brasileiras ou de fora, e até personalidades ilustres.

Todos esses atores deixam, de uma maneira ou de outra, a sua marca nos projetos, mas é difícil avaliar a influência de cada um. Num estudo sobre a patrimonialização do samba de roda, o etnomusicólogo Carlos Sandroni (2011, p. 240241, tradução minha) constata que os atores exteriores (funcionários, folcloristas, antropólogos, empregados da indústria cultural) ora se esforçam em "conservar as tradições na sua suposta pureza", ora "incentivam mudanças demasiado rápidas", e que, da mesma maneira, os próprios sambadores ${ }^{30}$ ora "se queixam de não poder dispor de um equipamento de som moderno", ora "se vangloriam

28 As comunidades de Itacoatiara-Mirim e Uaupuí Cachoeira contavam, respetivamente, com cerca de 100 e 250 habitantes no início dos anos 2010.

29 No caso da FSS, o xamanismo é, por exemplo, considerado como um patrimônio universal que deve ser reabilitado "para todos", em particular no Ocidente, onde foi "perdido" séculos atrás devido à "opressão religiosa”. A fundação apresenta-se como uma organização dedicada à preservação do saber xamânico “para o bem-estar do planeta e dos seus habitantes”. Fonte: apresentação dos objetivos da fundação no seu website (About..., [s.d.])

30 Segundo Sandroni (2011, p. 234), os praticantes do samba de roda da Bahia são denominados sambadores e sambadeiras, e não sambistas, como em outros lugares. 
de serem os melhores guardiões do samba 'eterno'". Tanto os atores institucionais quanto os grupos locais oscilam assim entre tendências "conservadoras" e "modernizantes". Isso acontece também entre os Baniwa. Os habitantes de Itacoatiara-Mirim, por exemplo, zelam pelo respeito de certas regras antigas, como a interdição às mulheres de ver as flautas sagradas, mas ao mesmo tempo aspiram a introduzir novidades nos costumes revitalizados. Durante um tempo, queriam fazer um chão de concreto na maloca, porque diziam que o chão de terra produzia muita poeira; e pediam aos visitantes para os quais organizavam podáali que trouxessem itens industrializados (frangos congelados, caixas de cerveja, bolacha, etc.). Enquanto isso, seus parceiros brancos importam para a comunidade "novas tecnologias" (computadores, câmera, vara com microfone, etc.), mas valorizam ao mesmo tempo elementos considerados como tradicionais (o chão de terra da maloca, o serviço de caxiri - e não de cerveja - nos podáali, o uso de pinturas corporais, etc.). Resulta, assim, quase impossível distinguir os aportes das diferentes categorias de atores. Da mesma maneira, não se pode identificar com certeza os instigadores dos projetos. As iniciativas são sem dúvida elaboradas localmente pelos habitantes das comunidades indígenas, mas não nasceriam sem o incentivo das instituições, que oferecem oportunidades de financiamento, e sem a ajuda dos atores intermediários, que traduzem as aspirações locais na linguagem burocrática das instâncias financiadoras. Nos dois casos estudados, podemos assinalar também a influência de projetos anteriores (um projeto de "medicina tradicional" desenvolvido por grupos indígenas do Uaupés e os projetos bem-sucedidos das comunidades rivais do médio Içana no caso dos Hohodene de Uaupuí Cachoeira; e vários projetos de "desenvolvimento sustentável" no caso dos habitantes de Itacoatiara-Mirim) na vontade das famílias Hohodene de criar "projetos" de revitalização cultural.

Se as formas históricas de pajelança baniwa já eram afetadas pelos contatos interétnicos, as suas expressões atuais são o fruto direto das interações dos Baniwa com outros grupos indígenas e, sobretudo, com uma vasta gama de atores brancos, provenientes de lugares e setores sociais variados.

Outra caraterística dos fenômenos de patrimonialização, além da sua propensão a florescer em contextos cosmopolitas, é a sua tendência a produzir a revalorização de certos itens culturais e seu "deslocamento". Para Bondaz, Isnart e Leblon (2012, p. 9, tradução minha), esses fenômenos constituem "processos complexos de seleção e requalificação que envolvem [mettent en jeu] 
valores mais ou menos partilhados, reconhecidos e estabelecidos ao longo do tempo" e "implicam uma transferência do item [patrimonializado] para uma nova esfera da sociedade" (Bondaz; Isnart; Leblon, 2012, p. 10, tradução minha).

No caso dos projetos da Escola de Pajelança e do documentário Podáali, elementos como as festas de troca podáali, os saberes xamânicos e o ritual Kowai, que tinham sido desqualificados - primeiro pelos missionários brancos e depois pelos líderes evangélicos baniwa -, foram revalorizados. Não o foram para a totalidade do grupo baniwa, pois ainda suscitam desaprovação entre os evangélicos, mas para os habitantes de Uaupuí Cachoeira e Itacoatiara-Mirim e seus parceiros. Através desse processo, esses elementos foram dissociados dos seus antigos usos e "transferidos" a uma nova esfera social. Não formam mais parte de uma "instituição" central na vida do grupo, como antigamente, nem se limitam às curas quase secretas realizadas pelos benzedores. Em Uaupuí Cachoeira como em Itacoatiara-Mirim, as práticas e os saberes xamânicos foram "transferidos" para a área pública das relações exteriores, onde são mobilizados para atrair visitantes, ganhar visibilidade no cenário político regional e captar financiamentos e outros recursos materiais que lhes fazem falta. Nesse sentido, podemos vê-los como instrumentos diplomáticos, ou seja, como dispositivos usados para defender os interesses de comunidades locais num cenário político amplo, que inclui aldeias indígenas concorrentes e autoridades "brancas" historicamente pouco preocupadas com o destino dos moradores das comunidades indígenas.

\section{Considerações finais}

Em alguns aspectos, essas expressões contemporâneas da pajelança baniwa evocam as novas formas de xamanismo comumente denominadas "neoxamanismos" (Langdon, 2013). A categoria de "neoxamanismo" remete a práticas xamânicas que emergiram recentemente em várias regiões do mundo em resposta ao interesse crescente do público ocidental por rituais exóticos. Nas últimas décadas, multiplicaram-se nos Estados Unidos e na Europa organismos (como a FSS), seminários e festivais dedicados à transmissão e promoção de atividades e saberes xamânicos, enquanto nas áreas geográficas consideradas como berços do xamanismo, como a Sibéria, o México e a Amazônia, apareceram "empresas" ou "centros" xamânicos abertos a uma clientela de viajantes 
estrangeiros. Na Amazônia peruana, por exemplo, surgiram a partir dos anos 1990 vários centros xamânicos resultando de parcerias entre ocidentais e indígenas ou mestiços que oferecem atividades centradas no consumo de ayahuasca, uma bebida considerada como um poderoso alucinógeno (Losonczy; Mesturini Cappo, 2010).

As expressões atuais da pajelança baniwa distinguem-se, porém, dessas novas formas de xamanismo, pois apesar de resultar de relações com os brancos, não estão explicitamente dirigidas a um público ocidental. O público que frequenta os centros xamânicos da Amazônia peruana está em grande medida formado por turistas estrangeiros em busca de exotismo, experiências espirituais e terapias alternativas. Recrutado principalmente entre as classes médias e altas urbanas da América do Norte e da Europa, pertence geralmente aos setores intelectuais e artísticos, das profissões liberais e dos altos níveis das empresas multinacionais. Trata-se também de um público em maioria feminino que, geralmente, já está envolvido no mundo das terapias num sentido amplo (Losonczy; Mesturini Cappo, 2010, p. 94). Ora, no Alto Rio Negro, onde o turismo é apenas incipiente, não chegam muitos viajantes estrangeiros com esse perfil. Além disso, os projetos implementados pelas famílias Hohodene não deram origem a estruturas institucionalizadas. Foram iniciativas familiais pontuais cujas conexões com organismos nacionais e internacionais eram indiretos e efêmeros.

Uma denominação mais adequada que a de "neoxamanismo" para designá-las poderia ser a de "xamanismo de interface" utilizada por Anne-Marie Losonczy e Silvia Mesturini Cappo (2013). As duas antropólogas estabelecem uma distinção entre os "xamanismos vernaculares", praticados por e para grupos indígenas determinados, os "xamanismos de interface", que, desde o período colonial, nasceram das situações de contato entre índios e brancos ou mestiços, e os "xamanismos globalizados", formados por redes internacionais e influenciados pelo New Age. ${ }^{31} \mathrm{O}$ "xamanismo de interface" remete na sua perspectiva a uma formação xamânica caraterizada por uma grande plasticidade ritual que, em situações de encontros entre populações indígenas e "brancas",

31 O New Age é um movimento de contornos pouco definidos, mas podemos considerá-lo como uma "grande bricolagem espiritual e cultural" nascido nos Estados Unidos nos anos 1960 e articulado ao redor de uma mensagem milenarista que anuncia um renascimento definido como "a superação da hegemonia das grandes religiões que acompanharam as empresas coloniais bem como a tirania da economia de mercado" (Losonczy; Mesturini Cappo, 2013, p. 10, tradução minha). 
"coexistiu primeiro com a religião católica oficial e as práticas do catolicismo popular, depois [com] a biomedicina e as religiões evangélicas, dentro de uma economia cada vez mais globalizada" (Losonczy; Mesturini Cappo, 2013, p. 10, tradução minha). À diferença do que acontece no xamanismo "globalizado", ainda existe nele uma transmissão dos saberes rituais entre as gerações, e conserva um alcance regional (Losonczy; Mesturini Cappo, 2013, p. 12). Essas características correspondem bastante bem às formas contemporâneas da pajelança baniwa, que têm mais sucesso no "exterior" do grupo que dentro dele, mas que permanecem praticadas na região do Alto Rio Negro.

\section{Referências}

ABOUT The Foundation for Shamanic Studies. The Foundation for Shamanic Studies, [s.d.]. Disponível em: <https://www.shamanism.org/fssinfo/index.html>. Acesso em: 12 abr. 2017.

BANIWA Shamanic Revitalization and Living Treasure Jaguar-Shaman Mandu Silva. Foundation for Shamanic Studies, 8 jul. 2009. Disponível em: <https://shamanism. org/news/foundation-supports-last-jaguar-shaman/>. Acesso em: 12 abr. 2017.

BONDAZ, J.; ISNART, C.; LEBLON, A. Au-delà du consensus patrimonial. Civilisations, n. 61-1, p. 9-21, 2012.

BORTOLOTTO, C. From objects to processes: UNESCO's “Intangible Heritage". Journal of Museum Ethnography, n. 19, p. 21-33, 2007.

BORTOLOTTO, C. Le trouble du patrimoine culturel immatériel. In: BORTOLOTTO, C. (Ed.). Le patrimoine culturel immatériel: enjeux d'une nouvelle catégorie. Collab. A. Arnaud et S. Grenet. Paris: Éditions de la Maison des Sciences de l'Homme, 2011. p. 21-43.

CAPREDON, E. Les églises autonomes: évangélisme, chamanisme et mouvement indigène chez les Baniwa de l'Amazonie brésilienne. 2016. Thèse (Doctorat en Anthropologie)-École des Hautes Études en Sciences Sociales, Paris; Universidade Estadual do Rio de Janeiro, Rio de Janeiro, 2016.

CHAUMEIL, J.-P. Voir, savoir, pouvoir: le chamanisme chez les Yagua du Nord-Est péruvien. Paris: Éditions de l'École des Hautes Études en Sciences Sociales, 1983.

CHAUMEIL, J.-P. El comercio de la cultura: el caso de los pueblos amazónicos. Bulletin de l'Institut Français d'Études Andines, v. 38, n. 1, p. 61-74, 2009.

CLASTRES, P. La société contre l'État. Paris: Minuit, 2011. 
GALVÃO, E. Aculturação indígena no Rio Negro. Boletim do Museu Paraense Emílio Goeldi, Belém, n. 7, p. 1-59, 1959.

GARNELO, L. Poder, hierarquia e reciprocidade: os caminhos da política e da saúde no Alto Rio Negro. 2002. Tese (Doutorado em Ciências Sociais)-Instituto de Filosofia e Ciências Humanas, Universidade Estadual de Campinas, Campinas, 2002.

GLOBO AMAZÔNIA. Aldeia indígena do Amazonas ganha escola de xamanismo. Extra, 14 jan. 2010. Disponível em: <http://extra.globo.com/noticias/brasil/aldeia-indigena-do-amazonas-ganha-escola-de-xamanismo-73164.html>. Acesso em: 28 abr. 2017.

GOLDMAN, I. Tribes of the Uaupés-Caquetá Region. In: STEWARD, J. (Ed.). Handbook of South American Indians: vol. 3: the tropical forest tribes. Washington, DC: Smithsonian Institution, 1948. p. 763-798.

HUGH-JONES, S. The palm and the Pleiades: initiation and cosmology in Northwest Amazonia. Cambridge: Cambridge University Press, 1979.

INSTITUTO SOCIOAMBIENTAL (ISA). Inaugurada Escola de Xamã no Rio Aiari, na Terra Indígena Alto Rio Negro (AM). 13 set. 2008. Disponível em: <https://site-antigo. socioambiental.org/nsa/detalhe?id=3023>. Acesso em: 28 abr. 2017.

KOCH-GRÜNBERG, T. Dois anos entre os indígenas: viagens no noroeste do Brasil (1903-1905). Manaus: Editora da Universidade Federal do Amazonas: Faculdade Salesiana Dom Bosco, 2005.

LANGDON, E. J. New perspectives of shamanism in Brazil. Shamanisms and neo-shamanisms as dialogical categories. Civilisations, n. 61-2, p. 19-35, 2013.

LIMA FILHO, M. F.; ABREU, R. M. do R. M. La antropología y el patrimonio cultural en Brasil. Revista Colombiana de Antropología, Bogotá, v. 46, p. 133-155, 2010.

LIVING Treasure Mandu Manoel da Silva. The Foundation for Shamanic Studies, [s.d.]. Disponível em: <https://www.shamanism.org/fssinfo/livingtreasuredaSilva.html>. Acesso em: 12 abr. 2017.

LOSONCZY, A.-M.; MESTURINI, S. Entre l'“Occidental” et l'“Indien”. Ethnographie des routes du chamanisme ayahuasquero entre Europe et Amériques. Autrepart, v. 56, n. 4, p. 93-110, 2010.

LOSONCZY, A.-M.; MESTURINI CAPPO, S. Introduction au dossier "Chamanismes en mouvement". Civilisations, n. 61-2, p. 7-18, 2013.

MAUÉS, R. H. Uma outra “invenção” da Amazônia: religiões, histórias, identidades. Belém: Cejup, 1999. 
MONTARDO, D. A música indígena no mundo dos projetos: etnografia do Projeto Podáali - valorização da música Baniwa. Trans: Revista Transcultural de Música, n. 15, p. 1-13, 2011.

NIMUENDAJÚ, C. Reconhecimento dos rios Içana, Ayarí e Uaupés. Journal de la Société des Américanistes, n. 39, p. 125-182, 1950.

PRAZERES, L. Malikai Dapana: a escola de pajés. Povos Indígenas no Brasil, 23 maio 2010. Disponível em: <https://pib.socioambiental.org/pt/noticias?id=85416 $>$. Acesso em: 28 abr. 2017.

REICHEL-DOLMATOFF, G. Amazonian cosmos: the sexual and religious symbolism of the Tukano Indians. Chicago: University of Chicago Press, 1971.

ROBBINS, J. Becoming sinners: christianity and moral torment in a Papua New Guinea Society. Berkeley: University of California Press, 2004.

SANDRONI, C. L'ethnomusicologue en médiateur du processus patrimonial. Le cas de la samba de roda. In: BORTOLOTTO, C. (Ed.). Le patrimoine culturel immatériel: enjeux d'une nouvelle catégorie. Collab. A. Arnaud et S. Grenet. Paris: Éditions de la Maison des Sciences de l'Homme, 2011. p. 233-250.

SIASI/SESAI. Dados populacionais de 2013 das etnias cadastradas no SIASI por distrito sanitário especial indígena - DSEI: Distrito Alto Rio Negro. 2013. Disponível em: <http://dw.saude.gov.br/gsid/servlet/mstrWeb?src=mstrWeb.2048001\&evt=204800 $1 \&$ share=1\&hiddensections=header\%2Cpath\%2CdockLeft\%2Cfooter\&visMode=0\&c urrentViewMedia=2\&documentID=5DECC34E11E3629D00000080EF2535D4\&Serv er=SRVBIPDFO3\&Port=0\&Project=DMSIASI_4\&>. Acesso em: 12 abr. 2017.

UNESCO. Actas de la Conferencia General: 25a reunión. París, 17 oct.-16 nov. 1989. Disponível em: <http://unesdoc.unesco.org/images/0008/000846/084696S.pdf>. Acesso em: 12 abr. 2017.

WRIGHT, R. Cosmos, selfand history in Baniwa religion: for those unborn. Austin: University of Texas Press, 1998.

WRIGHT, R. O tempo de Sophie: história e cosmologia da conversão baniwa. In: WRIGHT, R. (Ed.). Transformando os deuses: vol. I: os múltiplos sentidos da conversão entre os povos indígenas no Brasil. Campinas: Editora da Unicamp, 1999. p. 155-215.

WRIGHT, R. The wicked and the wise men: witches and prophets in the history of the Northwest Amazon. In: WHITEHEAD, N.; WRIGHT, R. (Ed.). In darkness and secrecy: the anthropology of assault sorcery in Amazonia. Durham: Duke University Press, 2004a. p. 82-108. 
WRIGHT, R. As tradições proféticas e cosmologias 'cristãs' entre os Baniwa. In: WRIGHT, R. (Ed.) Transformando os deuses: vol. II: igrejas evangélicas, pentecostais e neopentecostais entre os povos indígenas no Brasil. Campinas: Editora da Unicamp, 2004b. p. 377-402.

WRIGHT, R. História indígena e do indigenismo no Alto Rio Negro. São Paulo: ISA: Mercado de Letras, 2005.

WRIGHT, R. The art of being crente: the Baniwa protestant ethic and the spirit of sustainable development. Identities, n. 16, p. 202-226, 2009.

WRIGHT, R. Mysteries of the jaguar shamans of the Northwest Amazon. Lincoln: Boards of Regents of the University of Nebraska, 2013.

WRIGHT, R.; HILL, J. History, ritual and myth: nineteenth century millenarian movements in the Northwest Amazon. Ethnohistory, v. 33, n. 1, p. 31-54, 1986.

XAVIER, C. L. Os Koripako do Alto Içana: etnografia de um grupo indígena evangélico. 2013. Tese (Doutorado em Antropologia Social)-Museu Nacional, Universidade Federal do Rio de Janeiro, Rio de Janeiro, 2013. 